\title{
A great leap forward for ArgoSpine news and journal (ASN\&J)!
}

\author{
Christian Mazel $\cdot$ Pierre Kehr
}

Received: 28 February 2013/Accepted: 1 March 2013/Published online: 10 March 2013

(C) Springer-Verlag France 2013

ASN\&J-the journal of ArgoSpine association-which has been published for several years by Springer-Verlag France at the rate of four issues a year, has merged with "European Journal of Orthopaedic Surgery and Traumatology (EJOST)" also published by Springer-Verlag France as from 2013.

The four issues will be condensed into two issues in the form of supplements to the eight regular EJOST issues. The first supplement of 2013, which is now in your hands, includes Original Articles, General Reviews and a few clinical cases (Up-to-date Reviews and Case Reports) in the field of spine care, as well as the synthesis of the ArgoSpine congress held in January 2013. This scientific supplement will be released in the same form every year between June and August. A second supplement will be out every year in January and will serve as the Scientific Book of the ArgoSpine annual symposium. The 2013 Scientific Book has been published still under the name of ASN\&J, whereas the 2014 edition will be the first 2014 supplement to EJOST.

ArgoSpine association will therefore be in a position to gain a wide readership, of over 50,000 worldwide, through more than 360 packages in which EJOST is included, with the benefit of improved visibility since EJOST has just been accepted for indexing in Medline/Pubmed in January 2013.

It is with great pride and satisfaction that the Editorial Board of EJOST introduces these two EJOST-ArgoSpine supplements thus offering a specific platform to the many orthopaedic surgeons, to neurosurgeons and to all the specialists dealing with spine surgery and care. 